\title{
PENDUGAAN FUNGSI PENAWARAN EKSPOR RUMPUT LAUT INDONESIA DI PASAR INTERNASIONAL Analisis Pendekatan Error Correction Model (ECM)
}

\author{
Risna Yusuf ${ }^{1}$ dan Tajerin ${ }^{1}$
}

\begin{abstract}
Abstrak:
Kajian ini bertujuan untuk menduga faktor-faktor yang mempengaruhi penawaran ekspor rumput laut Indonesia di pasar Internasional dengan menggunakan data runut waktu (time series data) tahun 1975 hingga 2005. Pendugaan persamaan penawaran ekspor rumput laut tersebut dilakukan dengan pendekatan metoda koreksi kesalahan (Error Corection Model-ECM). Hasil analisis menunjukkan bahwa penawaran ekspor rumput laut Indonesia ke pasar internasional dipengaruhi oleh produksi, harga ekspor, pendapatan nasional bruto negara mitra dagang, nilai tukar rupiah dan ekspor rumput laut Indenesia tahun lalu dengan arah perubahan yang sama (positif), dan harga domestik dan tingkat suku bunga dengan arah perubahan yang berlawanan (negatif). Oleh karena itu, perlu kesungguhan pemerintah bersama nelayan/pembudidaya \& eksportir rumput laut untuk menjaga mutu; dan lebih meningkatkan kerjasama perdagangan dengan negara mitra dagang Indonesia (Importir), demikian juga dengan negara produsen lainnya.
\end{abstract}

\section{Kata Kunci: Penawaran Ekspor, Rumput Laut, Pasar Internasional, ECM}

\section{Abstract: The Estimation of Indonesian Seaweed Export Supply Function in the International Market : Analysis of Error Correction Model(ECM) By: Risna Yusuf and Tajerin}

The aim of the research was to estimate the factors affecting Indonesian seaweed export supply in international market using secondary time series data from 1975 until 2005. The estimation of supply was done using error correction model (ECM). The results show that export supply of Indonesian seaweed in international markets is affected by production, export price, gross national product, exchange rate, and lagged export of Indonesian seaweed which all have positive signs. On the other hand domestic price and interest rate have negative signs. Therefore, the government, fishers/seaweed farmers and seaweed exporter must pay more attention on seaweed quality and trade cooperation with importer and other producers.

Keywords : Export Supply, Seaweed, International Market, ECM

\section{PENDAHULUAN}

Salah satu komoditas nonmigas dari sub sektor perikanan yang memiliki potensi ekspor yang cukup besar adalah rumput laut. Dilihat dari potensi lahan untuk pengembangan budidayanya yang seluas 1,1 juta ha, diperkirakan mampu memproduksi sebanyak 17,7 juta ton rumput laut per tahun. Oleh karena itu, cukup rasional bila Indonesia sesungguhnya memiliki peluang yang besar untuk menjadi produsen rumput laut terkemuka di dunia (Dahuri, 2004 ; 2004 ${ }^{\mathrm{b}}$ ).

Di samping itu, dari aspek keragaman hayatinya, perairan Indonesia tercatat memiliki sebanyak 555 jenis rumput laut. Dari jumlah tersebut, jenis rumput laut yang mempunyai nilai ekonomis penting adalah jenis-jenis yang termasuk ke dalam kelas

\footnotetext{
${ }^{1}$ Peneliti pada Balai Besar Riset Sosial Ekonomi Kelautan dan Perikanan

JI. KS. Tubun Petamburan VI, Jakarta 10260

Telp. $02153650162 / F a x .02153650159$
} 
Rhodophyceae atau alga merah. Tiga marga penting dari alga merah tersebut yaitu Eucneuma (mengandung keragian) serta Gracilaria, Hypnea dan Gelidium (mengandung agar-agar). Ketiga marga rumput laut tersebut sudah sejak lama menjadi komoditi ekspor rumput laut Indonesia (Ma'ruf, 2005).

Jenis Eucheuma dan Gelidium yang seluruhnya diekspor dalam bentuk rumput laut kering, sedangkan jenis Gracilaria dan Hypnea selain diekspor juga dikonsumsi di dalam negeri sebagai bahan baku pembuatan agar-agar (Direktorat Jenderal Perikanan Budidaya, 2004). Dari total permintaan dunia terhadap jenis rumput laut yang mengandung karaginan rata-rata mencapai 18.000-20.000 ton setiap tahunnya. Dari jumlah ini, sebanyak 8 - 10\% (2000 ton) dipasok dari Indonesia pada setiap tahunnya.Sedangkan sisanya dipasok oleh negara lain terutama Philipina yang mencapai kurang lebih $80 \%$ dari total permintaan rumput laut di pasar internasional. Permintaan rumput laut tersebut diperkirakan akan terus mengalami peningkatan seiring dengan meningkatnya jumlah penduduk dari negara konsumen (Ma'ruf, 2005).

Hal ini mengindikasikan adanya sejumlah permintaan rumput laut dari negara konsumen yang harus diperebutkan oleh negara-negara produsen. Dengan kata lain terdapat potensi pasar untuk komoditas rumput laut di negaranegara konsumen yang harus diperebutkan oleh negara produsen khususnya Indonesia dan Philipina. Untuk memenuhi potensi pasar tersebut, Indonesia harus mampu bersaing di pasar internasional khususnya terhadap Philipina sebagai produsen terbesarnya. Sebagai langkah awal diperlukan data dan informasi berkaitan dengan penawaran ekspor rumput laut Indoensia di pasar internasional. Oleh karena itu kajian ini dilakukan dengan tujuan untuk melakukan pendugaan fungsi penawaran ekspor rumput laut Indonesia di pasar internasional. Hasil kajian ini diharapkan dapat bermanfaat sebagai bahan masukan bagi penentu kebijakan yang terkait dengan pengembangan budidaya dan kinerja ekspor komoditas rumput laut Indonesia.

\section{METODE}

Pada dasarnya pendekatan yang digunakan dalam studi ini bertumpu pada analisis penawaran ekspor rumput laut. Analisis penawaran rumput laut sangat bermanfaat bagi pengembangan rumput laut itu sendiri, bagi pembudidaya dan negara secara keseluruhan. Di tingkat pembudidaya hal tersebut tidak saja bisa menimbulkan surplus produksi dan mis-alokasi sumberdaya, namun lebih jauh lagi dapat menyebabkan kurangnya rangsangan bagi pembudidaya untuk meningkatkan produksi lebih lanjut. Dalam kaitan itu, sebagai langkah awal diperlukan pemahaman mengenai perilaku penawaran akan rumput laut, yaitu menyangkut faktor-faktor yang mempengaruhi penawaran, dan bagaimana penawaran tersebut bekerja dalam sistem pasar

\section{Landasan Teoritis \\ Penawaran ekspor}

Analisis penawaran ekspor di pasar internasional dapat dilakukan secara sederhana dengan menggunakan konsep dasar fungsi penawaran domestik untuk kasus dua negara dengan suatu komoditi perdagangan tertentu, misalnya rumput laut. Misalkan bahwa penawaran rumput laut di pasar domestik, masing-masing adalah $S^{A}$ di negara $A$ serta $S^{B}$ di negara $B$, seperti diilustrasikan secara grafik dalam Gambar 1.

Tanpa perdagangan, keseimbangan di negara $A$ dicapai pada kondisi $E^{A}$ dengan volume transaksi $Q_{0}^{A}$ dan harga $P^{A}$. Di negara $B$ keseimbangan dicapai pada kondisi $E^{B}$ dengan volume transaksi $Q_{0}^{B}$ dan harga $P^{B}$. Dengan asumsi bahwa harga domestik di negara $A$ relatif lebih murah dibandingkan dengan harga domestik di negara B. Untuk harga di atas $\mathrm{P}^{\mathrm{A}}$, produsen di negara $\mathrm{A}$ akan menghasilkan lebih banyak dari pada yang bersedia dibeli konsumen di negara tersebut. 


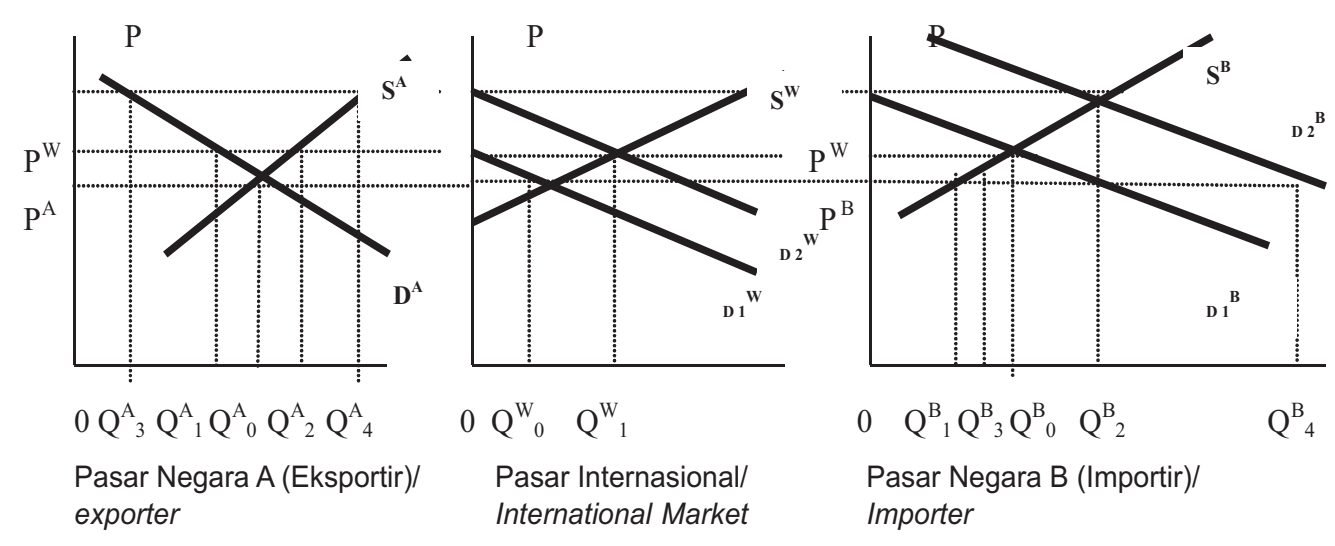

\section{Gambar 1. Model Keterkaitan Penawaran dan Permintaan di Pasar Domestik dengan Penawaran Ekspor dan Permintaan Impor di Pasar Internasional}

Picture 1. Model of Linkage of Supply and Demand on Domestic Market with Export Offer and Import Demand in International Market

Jadi fungsi penawaran $S^{A}$ di atas titik $E^{A}$ dapat mencerminkan excess supply function di negara A. Selanjutnya dimisalkan ada perdagangan antara $\mathrm{A}$ dan $\mathrm{B}$, dan andaikan biaya transportasi adalah nol. Penawaran ekspor pada pasar internasional digambarkan oleh $\mathrm{S}^{\mathrm{x}}$ yang tak lain adalah excess supply function dari negara $A$. Keseimbangan di pasar dunia terjadi pada titik $E^{\mathrm{W}}$ yang menghasilkan harga dunia sebesar $\mathrm{P}^{\mathrm{w}}$, dimana negara $A$ mengekspor sebesar $\left(Q^{A}{ }_{1}-\right.$ $Q^{A}{ }_{2}$ ). Jumlah ekspor tersebut ditunjukan volume perdagangan sebesar $Q^{W}$ pada pasar internasional.

Dalam pengertian lebih luas, ekspor suatu negara merupakan kelebihan penawaran domestik atau produksi barang atau jasa yang tidak dikonsumsi konsumen negara tersebut atau tidak disimpan dalam bentuk stok (Labys, 1973; Kindleberger and Lindert, 1982). dengan pengertian ini maka ekspor rumput laut dapat didefinisikan sebagai berikut:

$$
\mathrm{X}_{\mathrm{t}}=\mathrm{Q}_{\mathrm{t}}-\mathrm{C}_{\mathrm{t}}+\mathrm{S}_{\mathrm{t}-1}
$$

dimana:

$$
\begin{aligned}
\mathrm{Xt}= & \text { jumlah ekspor rumput laut pada } \\
& \begin{array}{l}
\text { tahun } \mathrm{t} / \text { export volume of seaweed at } \\
\text { tperiod }
\end{array} \\
\mathrm{Qt}= & \text { jumlah produksi rumput laut } \\
& \begin{array}{l}
\text { pada tahun } \mathrm{p} / \text { production volume of } \\
\text { seaweed at period }
\end{array} \\
\mathrm{Ct}= & \text { jumlah konsumsi rumput laut } \\
& \begin{array}{l}
\text { pada tahun } \mathrm{t} / \text { consumtion volume of } \\
\text { seaweed at period }
\end{array} \\
\mathrm{S}_{\mathrm{t}-1}= & \text { jumlah stok rumput laut pada } \\
& \text { tahun } \mathrm{t} / \text { stock volume of seaweed at } t \\
& \text { period }
\end{aligned}
$$

Konsumsi domestik negara produsen pada umumnya relatif stabil sehingga dapat diabaikan. Mengingat besarnya tingkat produksi rumput laut dibandingkan dengan permintaannya, maka kalaupun terdapat stok di negara produsen diduga bukanlah berfungsi sebagai penyangga (buffer) untuk mengatur kondisi pasar, Namun merupakan sisa produksi pada akhir tahun yang tidak dapat disalurkan di pasar internasional. Dengan demikian pola produksi rumput laut 
akan konsisten dengan pola penawaran ekspor, sehingga titik tolak selanjutnya adalah berapa besar keuntungan yang diperoleh produsen melalui penawaran ekspor. Hal ini dapat tercermin melalui harga ekspor yang diharapkan, sehingga fungsi penawaran ekspor dapat diturunkan sebagai berikut:

$$
X_{t}=f\left(P^{*}\right)
$$

Harga harapan ekspor dapat diduga dengan menggunakan Cagan's adaptif Expectation Model (Pindyck and Rubinfeld, 1991; Koutsyiannis, 1977)

$$
P_{t}^{*}-P_{t-1}^{*}=\theta\left(P_{t}^{*}-P_{t-1}^{*}\right)
$$

dimana:

$$
\begin{aligned}
\mathrm{P}_{\mathrm{t}}^{*}= & \text { harga harapan ekspor rumput } \\
& \text { laut/expected price of exported } \\
& \text { seaweed } \\
\mathrm{P}_{\mathrm{t}}= & \text { harga ekspor rumput laut } \\
& \text { aktual/actual price of exported } \\
& \text { seaweed } \\
\theta= & \text { koefisien harapan /expectation } \\
& \text { coefficient, dimana } 0<\theta \leq 1 \\
\mathrm{P}_{\mathrm{t}-1}^{*}= & \text { harga harapan ekspor rumput laut } \\
& \text { pada tahun t-1/expected price of } \\
& \text { exported seaweed attperiod }
\end{aligned}
$$

Dengan memasukan persamaan (3) ke persamaan (2) diperoleh:

$$
X_{t}=f\left(P_{t}, X_{t-1}\right)
$$

Penawaran ekspor suatu negara juga dipengaruhi oleh tingkat bunga dan nilai tukar valuta asing di negara pengekspor dan di negara partner dagang negara pengekspor (Branson and Litvack, 1981). Demikian juga berbagai kebijaksanaan pemerintah maupun kebijaksanaan internsional, tidak kalah pentingnya dalam mempengaruhi keragaman ekspor rumput laut suatu negara. Dengan menggabungkan faktor-faktor tersebut dengan persamaan (4), maka fungsi penawaran ekspor rumput laut suatu negara dalam bentuk dinamis dapat diturunkan sebagai berikut:

$X_{t}=f\left(P_{t}, X_{-1}, P S_{t}, E_{t}, Z_{t}\right)$

dimana:

$\mathrm{P}_{\mathrm{t}} \quad=$ harga ekspor rumput laut pada tahun t/price of exported seaweed at $t$ period

$\mathrm{PS}_{\mathrm{t}}=$ harga rumput laut dari negara mitra dagang pada tahun t/price of importer seaweed from

$\mathrm{E}_{\mathrm{t}} \quad=$ nilai tukar mata uang asing pada tahun $\mathrm{t} /$ trading partner at t period

$Z_{\mathrm{t}} \quad$ = faktor-faktor lain yang mempengaruhi ekspor rumput laut pada tahun t/other factors effect on exported seaweed at $t$ period

$\mathrm{Xt}_{-1}=$ volume ekspor rumput laut pada tahun t-1/volume of exported seaweed at $t-1$ period

Selanjutnya mekanisme perubahan harga rumput laut di pasar internasional dapat terjadi, baik karena kekuatan-kekuatan yang mempengaruhi perubahan penawaran ekspor. Sebagai komoditi yang diperdagangkan di pasar dunia, harga rumput laut sangat dipengaruhi oleh pola perdagangan yang terjadi. Ada dua variabel utama dalam perdagangan yang mempengaruhi harga rumput laut, yakni variabel eksternal dan internal. Variabel eksternal terutama adalah yang berkaitan dengan kebijaksanaan internasional dan variabel internal berkaitan dengan mekanisme pemasaran dan budidaya rumput laut, seperti produktivitas, rantai pemasaran dan mutu.

Dengan demikian fungsi harga rumput laut di pasar dunia dapat dirumuskan sebagai berikut:

$\mathrm{P}_{\mathrm{t}}^{\mathrm{W}}=\mathrm{f}\left(\mathrm{X}_{\mathrm{t}}, \mathrm{M}_{\mathrm{t}}, \mathrm{Z}_{\mathrm{t}}\right)$ 
dimana:

$$
\begin{aligned}
\mathrm{P}_{\mathrm{t}}^{\mathrm{w}}= & \text { harga rumput laut di pasar dunia } \\
& \text { pada tahun } \mathrm{t} \text { price of seaweed in } \\
& \text { world market at } t \text { period } \\
\mathrm{X}_{\mathrm{t}}= & \text { jumlah penawaran ekspor } \\
& \text { rumput laut pada tahun } \mathrm{t} / \text { supply } \\
& \text { volume of exported seaweed at } t \\
& \text { period } \\
\mathrm{M}_{\mathrm{t}}= & \text { jumlah permintaan ekspor } \\
& \text { rumput laut pada tahun } \\
& \text { t/demand volume of seaweed at } \\
& \begin{array}{l}
\text { tperiod lainnya yang } \\
\text { faktor-faktor laing }
\end{array} \\
& \text { mempengaruhi harga rumput } \\
& \text { laut di pasar dunia pada tahun } \mathrm{t} / \\
& \text { otherfactors effect on the price of } \\
& \text { seaweed in world market at } t \\
& \text { period }
\end{aligned}
$$

akan cenderung menurunkan/menaikkan penawaran ekspor rumput laut jenis lainnya. Kenaikan produksi rumput laut, depresiasi nilai rupiah terhadap dollar, demikian juga perubahan trend waktu, diharapkan cenderung akan mengingkatkan penawaran ekspor rumput laut Indonesia.

Akses pinjaman kredit dari Bank akan menambah modal kerja para eksportir untuk membeli rumput laut dari pembudidaya atau pedagang lokal untuk tujuan ekspor. Oleh karena itu kenaikan suku bungan pada pasar uang akan cenderung menurunkan penawaran ekspor. Sistem kuota diduga adalah merupakan faktor yang bias menurunkan ekspor rumput laut Indonesia.

Dengan demikian persamaan penawaran ekspor rumput laut Indonesia ke masingmasing wilayah tujuan ekspor dalam jangka panjang dapat dirumuskan sebagai berikut:

$$
\begin{aligned}
& \operatorname{LnXR}_{t}=\alpha_{0}+\alpha_{1} \operatorname{LnPXR_{t}}+\alpha_{2} \operatorname{LnQR}_{t-1}+\alpha_{3} \operatorname{LnGNP}_{t}+\alpha_{4} \operatorname{LnNTR}_{t} \\
& +\alpha_{5} \operatorname{LnINT}+\alpha_{6} \operatorname{LnXR_{t-1}}+U
\end{aligned}
$$

\section{Perumusan dan pendugaan model}

Penawaran ekspor rumput laut Indonesia dianalisis tidak berdasarkan jenis rumput laut namun agregat dari seluruh jenis tersebut, hal ini mengingat data ekspor dan harga per jenis rumput laut tidak tersedia secara lengkap. Peubah-peubah yang diduga berpengaruh terhadap penawaran ekspor rumput laut Indonesia adalah harga ekspor, produksi, nilai tukar rupiah terhadap Dollar, tingkat suku bunga, kebijaksanaan kuota ekspor rumput laut, kebijaksanaan standarisasi mutu rumput laut, dan trend waktu.

Perubahan harga ekspor masing-masing jenis rumput laut diharapkan akan cenderung mempengaruhi perubahan penawaran ekspor masing-masing jenis rumput laut tersebut dengan arah perubahan yang sama. Akan tetapi jika jenis rumput laut satu dengan lainnya adalah komoditi yang saling bersaing, maka kenaikan/penurunan harga ekspor salah satu jenis rumput laut bukan tidak mungkin dimana:

LnXRt = log. natural jumlah ekspor rumput laut Indonesia ke pasar Internasional (ton)/ natural log of export volume of Indonesian $s \quad e \quad a \quad w \quad e \quad e \quad d$ to International market (ton

LnPXRt $=$ log. natural harga riel ekspor rumput laut Indonesia di pasar internasional (Dollar/ton)/natural log of export riel price of Indonesian seaweed to International market (Dollar/ton)

LnQRt-1 = log. natural jumlah produksi rumput laut Indonesia tahun lalu (ton)/natural log production volume of Indonesian seaweed at previous year (ton)

LnGNPt $=$ log. natural pendapatan nasional negara Internasional 
(Milyar Dollar)/natural log of foreign country national income (billion Dollar)

LnNTRt $=$ log. natural nilai tukar $\begin{array}{llllllll}n & 0 & m & \mathrm{i} & \mathrm{n} & \mathrm{a} & \text { I }\end{array}$ rupiah terhadap dollar I $\mathrm{n} \mathrm{t}$ e $\mathrm{r} \mathrm{n}$ a s i o $\mathrm{n}$ a I (Rp/Dollar)/natural log of exchange rate Rupiah to Dollar (Rp/Dollar)

LnINTt = log. natural tingkat bunga nominal pasar uang Indonesia (\%/tahun)/natural log of interest rate of Indonesia market (\%/year)

LnXRt-1 = logaritma natural jumlah ekspor rumput laut l $n \quad d \quad o \quad n$ e $s$ i $a$ ke pasar Internasional pada satu tahun sebelumnya (ton)/natural log of export volume of Indonesian seaweed to Internatioanl market at previous year (ton)

Dt = dummy pemberlakuan kebijakan mutu ekspor rumput laut (1 bila diberlakukan; dan 0 lainnya)/dummy of policy of seaweed exported quality (1=applied, $0=$ other)

Ut $=$ peubah pengganggu/error

Tanda koefisien regresi yang diharapkan adalah: $\alpha_{1}, \alpha_{2}, \alpha_{3}, \alpha_{4}, \alpha_{6}>0$; dan $\alpha_{5}<0$.

Persoalan krusial dalam analisis perilaku data time series adalah bahwa data seringkali menunjukkan kondisi tidak stasioner. Jika data tidak stasioner pada tingkat level tetapi stasioner pada tingkat differensi serta data terkointegrasi maka regresi pada persamaan (9) akan menghasilkan regresi yang lancung (spurious regression). Menurut Engle and Granger (1987), perilaku antara peubah seringkali menunjukkan hubungan jangka pendek mungkin akan terjadi ketidakseimbangan (disequilibrium). Ketidakseimbangan inilah yang sering kita temui dalam perilaku data ekonomi. Apa yang digunakan pelaku ekonomi (desired) belum tentu sama dengan apa yang terjadi sebenarnya. Adanya perbedaan apa yang diinginkan dan apa yang terjadi maka diperlukan adanya penyesuaian (Engle and Granger, 1987). Model penyesuaian untuk melakukan koreksi bagi ketidakseimbangan dalam jangka pendek disebut sebagai model koreksi kesalahan (Error Correction Model ECM). Adapun model perilaku ekspor rumput laut Indonesia ke wilayah Internasional pada persamaan (7) dalam jangka pendek dapat dituliskan kembali sebagai berikut:

$\operatorname{LnXR}_{t}=\alpha_{\mathrm{o}}+\alpha_{1} \operatorname{LnPXR}_{t-1}+\alpha_{3} \operatorname{LnGNP}_{t}$
$+\alpha_{4} \operatorname{LnNTR}_{t}+\alpha_{5} \operatorname{LnINT+} \alpha_{3} \operatorname{LnXR}_{t-1}+\mathrm{U}_{t} . .(8)$
dimana D merupakan perbedaaan pertama (first difference) dan $E C_{t-1}$ adalah residual periode sebelumnya sebagai peubah koreksi kesalahan (error correction variable).

\section{Pengujian Unit Root}

Akhir-akhir ini telah timbul perhatian para peneliti ekonomi untuk menguji data runut waktu (time serie) yang mereka teliti apakah benar-benar bersifat stationary atau nonstationary. Perhatian ini timbul karena jika ternyata data runut waktu yang diteliti bersifat non-stationary seperti kebanyakan data ekonomi, maka hasil regresi yang berkaitan dengan data runut waktu ini akan mengandung $R^{2}$ (koefisien determinasi) yang relatif tinggi namun dengan nilai DW (DurbinWatson) statistik yang rendah seperti yang dibuktikan oleh Granger dan Newbold (1974; 1977). Sehingga, pelaksanaan analisis data akan dihadapkan dengan masalah regresi lancung (spurious regression) seperti yang dikemukakan Philips (1986).

Kestabilan suatu model runut waktu bermakna terkandungnya sifat stationary 
dalam model. Misalnya, dalam model runtu waktu yang berikut:

$$
Y_{t}=\beta Y_{t-1}+\mu_{t} ; u_{t} \approx \operatorname{NID}\left(0, \sigma^{2}\right)
$$

$\operatorname{NID}\left(0, \sigma^{2}\right)$ menunjukkan adanya normal distribution dengan rata-rata $=0$, varian yang tetap $=\sigma^{2}$ dan kovarian $=0$. Kondisi stationary dalam model persamaan (9) ini mengandung pengertian bahwa $/ \beta /<1$. Dalam hal ini perlu dilakukan pengujian null-hypothesis $\beta=1$ terhadap alternative hypothesis mengenai adanya unit root. Fuller (1976) dan Dickey dan Fuller (1979) telah mengembangkan prosedur pengujian unit root ini dengan prosedur pengujian sebagai berikut:

$$
\begin{aligned}
& Y_{t}=b_{1} Y_{t-1}+e_{1 t} \\
& Y_{t}=a_{2}+b_{2} Y_{t-1}+e_{2 t} \\
& Y_{t}=a_{3}+b_{3} Y_{t-1}+e_{3 t}
\end{aligned}
$$

Apabila nilai absolut $\beta<1$ dalam model persamaaan (9), maka nilai-nilai $b_{i}$ dari setiap model regresi persamaan (10) sampai (11) diperkirakan bersifat normal dan distribusi tstatistik menjadi $t_{i}=\left(b_{i}-\beta\right) /$ se $\left(b_{i}\right)$ yang akan mendekati $t_{n-k}$ di mana $k$ bernilai 1,2 atau 3 tergantung model regresi yang digunakan. Apabila $\beta=1$ dan model persamaan (9) merupakan model yang sebenarnya, maka distribusi empirik t-statistik adalah $\mathrm{t}_{\mathrm{i}}$ dan bukan $t_{n-k}$.

Misalnya, hasil-hasil regresi model persamaan (8) telah diperoleh dan besar sampel adalah 25 dan 100 observasi. Dengan membandingkan t-statistik yang tertera dalam tabel Dickey-Fuller dan yang dihitung melalui regresi masing-masing, dapat diambil kesimpulan mengenai keberadaan unit root. Untuk model regresi yang mengandung higher order autoregressive processes, pengujian stationary dapat dilakukan dengan pengujian Dickey-Fuller yang diperluas (Augmented Dickey-Fuller Test) dan Philip-Perron Test. Pengujian dilakukan dengan membandingkan nilai ADF t-statistik dengan nilai kritis dari MacKinnon (MCA). Jika ADF t-statistik lebih besar dari nilai kritisnya maka peubah tersebut adalah stasioner (Gujarati, 1995; Banerjee, 1997).

\section{Data dan Sumber Data}

Data yang digunakan dalam studi ini adalah data sekunder deret waktu (time series) selama periode tahun 1975-2005. Selain alasan ekonometrika, misalnya untuk memperbanyak jumlah contoh pengamatan, periode tersebut diharapkan dapat menjawab permasalahan khususnya yang berkaitan dengan pengaruh berbagai perubahanperubahan penting dalam dunia perdagangan rumput laut. Sumber data yang diharapkan adalah BPS, Deperindag, Bank Indonesia dan berbagai publikasi atau laporan-laporan lainnya yang berkaitan dengan penelitian.

\section{HASIL DAN PEMBAHASAN}

Isu penting menyangkut regresi dengan menggunakan data runut waktu (time series) adalah masalah stasionaritas. Regresi yang melibatkan dua atau lebih data runut waktu yang tidak stasioner akan menghasilkan regresi yang lancung (spurious regression). Oleh karena itu sebelum dilakukan analisis regresi, terlebih dahulu dilakukan uji stasioneritas.

\section{Uji Stasioner Data Menggunakan Unit Root Test}

Sebelum dilakukan analisis (pendugaan) terhadap persamaan yang digunakan dalam model, terlebih dahulu seluruh data yang digunakan harus berada pada kondisi yang stasioner. Hasil pengujian stasioner terhadap peubah-peubah yang digunakan dalam kajian ini tertera pada Tabel 1. 
Tabel 1. Hasil Uji Unit Root terhadap Peubah-Peubah yang Digunakan dalam Model Analisis Penawaran Ekspor Rumput Laut Indonesia di Pasar Internasional.

Table 1. Result of Unit Root Test to Variables in Analyzes Model Indonesian Seaweed Export Supply I in International Market.

Augmented Dickey Fuller

\begin{tabular}{ccccc}
\hline Peubah/ & \multicolumn{2}{c}{ Tingkat / Level } & \multicolumn{2}{c}{ Perbedaan Pertama / First Different } \\
\cline { 2 - 5 } & $\begin{array}{c}\text { Dengan } \\
\text { Konstanta/ } \\
\text { Constant }\end{array}$ & $\begin{array}{c}\text { Dengan konstanta } \\
\text { dan trend/ } \\
\text { Constant and Trend }\end{array}$ & $\begin{array}{c}\text { Dengan } \\
\text { konstanta/ } \\
\text { Constant }\end{array}$ & $\begin{array}{c}\text { Dengan konstanta } \\
\text { dan trend/ } \\
\text { Constant and Trend }\end{array}$ \\
\hline Ln XR & $-0,741120$ & $-1,032483$ & $-3,509115^{* *}$ & $-2,267452$ \\
Ln QR & $-0,187882$ & $-1,888417$ & $-4,967840^{* * *}$ & $-4,856303^{* * *}$ \\
Ln PXR & $-2,276656$ & $-3,585044^{*}$ & $-3,038472^{* *}$ & $-1,868347$ \\
Ln PDR & 0,304754 & $-2,682191$ & $-1,772017$ & $-1,575128$ \\
Ln GNP & $-1,081010$ & $-4,919970^{* * *}$ & $-7,342164^{* * *}$ & $-7,314739^{* * *}$ \\
Ln NTR & $-1,037707$ & $-2,846800$ & $-7,205243^{* * *}$ & $-7,176791^{* * *}$ \\
Ln INT & $-2,890255^{*}$ & $-3,345272^{*}$ & $-6,557741^{* * *}$ & $-6,559141^{* * *}$ \\
& & & & \\
TCV 1\% & $-3,670170$ & $-4,296729$ & $-3,679322$ & $-4,374307$ \\
$5 \%$ & $-2,963972$ & $-3,568379$ & $-2,967767$ & $-3,603202$ \\
$10 \%$ & $-2,621007$ & $-3,218382$ & $-2,622989$ & $-3,238054$ \\
\hline
\end{tabular}

Phillips-Perron

\begin{tabular}{ccccc}
\hline $\begin{array}{c}\text { Peubah/ } \\
\text { Variables }\end{array}$ & \multicolumn{2}{c}{ Tingkat Level } & \multicolumn{2}{c}{ Perbedaan Pertama / First Different } \\
\cline { 2 - 5 } & $\begin{array}{c}\text { Dengan } \\
\text { Konstanta/ } \\
\text { Constant }\end{array}$ & $\begin{array}{c}\text { Dengan konstanta } \\
\text { dan trend/ } \\
\text { Constant and Trend }\end{array}$ & $\begin{array}{c}\text { Dengan } \\
\text { konstanta/ } \\
\text { Constant }\end{array}$ & $\begin{array}{c}\text { Dengan konstanta } \\
\text { dan trend/ } \\
\text { Constant and Trend }\end{array}$ \\
\hline Ln XR & $-0,741120$ & $-1,376303$ & $-3,515164^{* *}$ & $-3,453488^{*}$ \\
Ln QR & $-0,246916$ & $-2,125576$ & $-4,997099^{* * *}$ & $-4,891841^{* * *}$ \\
Ln PXR & $-2,458954$ & $-3,037362$ & $-7,887597^{* * *}$ & $-14,34788^{* * *}$ \\
Ln PDR & $-2,634160^{*}$ & $-4,518001^{* * *}$ & $-6,808163^{* * *}$ & $-7,911315^{* * *}$ \\
Ln GNP & $-1,358083$ & $-4,943322^{* * *}$ & $-13,16485^{* * *}$ & $-14,36799^{* * *}$ \\
Ln NTR & $-1,049338$ & $-2,846800$ & $-7,645598^{* * *}$ & $-8,143247^{* * *}$ \\
Ln INT & $-2,890255^{*}$ & $-3,345272^{*}$ & $-7,349074^{* * *}$ & $-7,140167^{* * *}$ \\
& & & & \\
TCV 1\% & $-3,670170$ & $-4,296729$ & $-3,679322$ & $-4,309824$ \\
$5 \%$ & $-2,963972$ & $-3,568379$ & $-2,967767$ & $-3,574244$ \\
$10 \%$ & $-2,621007$ & $-3,218382$ & $-2,622989$ & $-3,221728$ \\
\hline
\end{tabular}

Dari Tabel 1 terlihat bahwa setelah dilakukan uji unit root baik dengan pendekatan Augmented Dickey Fuller (ADF) maupun Philip-Perron ternyata pada kondisi level, sebagian besar peubah belum stasioner baik dengan konstanta maupun konstanta dan trand, kecuali untuk peubah InINT, InPDR,
InPXR dan LnGNP. Selanjutnya pada kondisi first different dengan menggunakan ADF ternyata meskipun sebagian besar peubah telah stasioner, namun masih terdapat beberapa peubah (InXR, InPDR dan InPXR) yang belum stasioner baik dengan mengunakan konstanta maupun konstanta 
dan trend. Akan tetapi dengan menggunakan uji Phillip-Perron, semua peubah yang digunakan dalam kajian ini telah stasioner baik dengan menggunakan konstanta maupun konstanta dan trend. Dengan demikian dapat disimpulkan bahwa semua peubah ini dapat digunakan lebih lanjut ke persamaan penawaran ekspor rumput laut Indonesia di pasar internasional dengan menggunakan pendekatan Error Correction Model(ECM).

Dari hasil pendugaan terhadap persamaan penawaran ekspor rumput laut pada Tabel 1 terlihat bahwa $\mathrm{R}^{2}$ dalam model ini mengindikasikan bahwa peubah terikat (ekspor rumput laut Indonesia) diterangkan oleh peubah bebas (produksi rumput laut Indonesia, Harga ekspor rumput laut Indonesia, Harga domestik rumput laut Indonesia, Pendapatan Nasional Bruto, Nilai Tukar Rupiah, Suku bunga rupiah dan Bedakala Ekspor rumput laut Indonesia sebesar $70,62 \%$ sedangkan sisanya diterangkan oleh peubah lain yang tidak ada dalam model. Sedangkan F-stat dalam model ini menunjukkan bahwa secara bersamasama semua peubah bebas yang digunakan dalam model ini berpengaruh nyata terhadap peubah terikat $(X R)$ pada taraf nyata $\alpha=0.01$.

Sebelum membahas hasil pendugaan persamaan penawaran ekspor rumput laut Indonesia di pasar Internasional jangka pendek dengan pendekatan ECM (Tabel 2), langkah pertama adalah melakukan uji diagnosis apakah model jangka pendek penawaran ekspor memenuhi asumsi klasik. Uji autokorelasi dengan uji LM, uji White Heteroskedastisitas, uji normalitas melalui uji Jarque-Bera dan uji spesifikasi kesalahan dengan Ramsey ternyata secara keseluruhan menunjukkan bahwa ECM lolos dari uji asumsi klasik. Demikian pula, berdasarkan kriteria statitik angka $R^{2}$, statistik $F$ dan Statistik DW (Tabel 2), model penawaran

Tabel2. Hasil Pendugaan Penawaran Ekspor Rumput Laut Indonesia di Pasar Internasional Menggunakan Error Correction Model (ECM) Periode 1975-2005

Table 2. Estimation Results of Indonesian Seaweed Export Supply in International Market Using Error Correction Model (ECM), 1975-2005.

\begin{tabular}{|c|c|c|c|}
\hline Peubah/ Variables & $\begin{array}{c}\text { Koefisien Regresi/ Coefficient } \\
\text { of Regression }\end{array}$ & $\begin{array}{l}\text { Simpangan Baku/ } \\
\text { Standar Error }\end{array}$ & -hitung/t-statistics. \\
\hline $\begin{array}{l}\text { Intersep/Intercept } \\
D(L O G(Q R)) \\
D(L O G(P X R)) \\
D(L O G P D R)) \\
D(L O G(G N P)) \\
D(L O G(N T R)) \\
D(L O G(I N T)) \\
D(L O G(X R(-!) \\
R E S(-1)\end{array}$ & $\begin{array}{r}0,016865 \\
0,313876 \\
0,241138 \\
-0,266673 \\
0,198964 \\
0,079634 \\
-0,052434 \\
0,474889 \\
-0,000094\end{array}$ & $\begin{array}{l}0,025496 \\
0,141343 \\
0,081048 \\
0,080724 \\
0,078624 \\
0,074380 \\
0,097303 \\
0,152965\end{array}$ & $\begin{array}{c}0,661492 \\
2,220675^{* * *} \\
2,975189^{* * *} \\
-3,303529^{* * *} \\
1,222237^{* * *} \\
-2,1820588^{\text {ns }} \\
3,272367^{\text {ns }} \\
8,998154^{* * *}\end{array}$ \\
\hline $\begin{array}{l}R^{2}=0,706160 ; \quad R^{2}-a \\
\text { LM }(2)=0,217745 \\
\text { White }=1,619066 \\
\text { Jarque-Bera }=0,228\end{array}$ & $\begin{array}{l}\text { Ajusted }=0,582438 ; \quad F \text {-stat }=5,7076 \\
\text { (Probabilitas = 0,806539); ARCH (1) } \\
\text { (Probabilitas = 0,210951); RESET (2) } \\
\quad(\text { Probabilitas }=0,892)\end{array}$ & $\begin{array}{l}\text { F-Prob. }=0,000884 ; \\
=2,157549 \text { (Probabilitas } \\
=3,041288 \text { (Probabilitas }\end{array}$ & $\begin{array}{l}D w=1,906417 \\
s=0,154343) \\
s=0,098225)\end{array}$ \\
\hline \multicolumn{4}{|c|}{$\begin{aligned} \text { Keterangan/remarks : }{ }^{* * *} & =\text { nyata pada taraf/ significant at level } \alpha=99 \% \\
* * & =\text { nyata pada taraf significant at level } \alpha=95 \% \\
* & =\text { nyata pada taraf significant at level } \alpha=90 \% \\
\text { ns } & =\text { tidak signifikan/ unsignificant }\end{aligned}$} \\
\hline
\end{tabular}


ekspor yang digunakan dalam kajian ini valid secara statistik.

Setelah dilakukan diagnosis ternyata tidak adanya penyimpangan asumsi klasik, maka pertanyaan selanjutnya apakah ECM merupakan model yang tepat digunakan dalam menganalisis perilaku penawaran ekspor rumput laut Indonesia di pasar Internasional jangka pendek. Ketepatan validitas ECM bisa dilihat dari taraf nyata (signifikansi) koefisien koreksi kesalahan, yaitu kelambanan residual $\mathrm{EC}_{\mathrm{t}-1}$. Koefisien $E C_{t-1}$ bertanda positif dan nyata secara statistik pada $\alpha=0,1$. Tanda koefisien koreksi kesalahan sebesar 0,000094 menunjukkan bahwa tidak terjadi ketidakseimbangan dalam jangka pendek.

Hasil regresi perilaku penawaran ekspor rumput laut Indonesia di pasar Internasional jangka pendek menunjukkan bahwa tanda semua koefisien regresi sesuai dengan teori ekonomi, hal ini berarti bahwa berdasarkan kriteria ekonomi persamaan penawaran ekspor rumput laut Indonesia ke pasar Internasional tergolong valid secara ekonomi. Dari Tabel 2, diketahui bahwa peubah harga riil ekspor rumput laut Indonesia di pasar Internasional $\left(D P X R_{t}\right)$, produksi rumput laut tahun lalu $\left(\mathrm{DQR}_{\mathrm{t}-1}\right)$, pendapatan nasional negara Internasional $\left(G P_{t}\right)$, nilai tukar nominal rupiah terhadap US Dollar $\left(\mathrm{NTR}_{\mathrm{t}}\right)$, ekspor rumput laut Indonesia ke pasar Internasional pada tahun sebelumnya $\left(D_{X} R_{t-1}\right)$ masing-masing menujukkan tanda koefisien regresi yang positif, sedangkan untuk peubah tingkat bunga bank (DINT) dan harga rumput laut dalam negeri $\left(\mathrm{PDR}_{\mathrm{t}}\right)$ bertanda negatif. Hal ini terjadi jika dibandingkan dengan komoditas udang dan tuna yang sejak dulu telah ada, komoditas rumput laut ini masih relatif baru sehingga belum mendapat dukungan dari Bank Indonesia sehingga hal ini mempengaruhi kinerja ekspor rumput laut Indonesia di pasar internasional.

Dari hasil pendugaan pada Tabel 2, diketahui bahwa secara individual keseluruhan peubah penjelas yang digunakan dalam model analisis masing-masing menunjukkan pengaruh yang nyata terhadap perubahan peubah jumlah ekspor rumput laut Indonesia di pasar Internasional $\left(D X R_{t}\right)$ dalam jangka pendek kecuali peubah harga rumput laut dalam negeri (DPDR $)$ dan peubah tingkat bunga bank (DINT $)$. Peubah Produksi rumput Laut ( $\left.D Q R_{t}\right)$, peubah jumlah ekspor rumput laut tahun sebelumnya $\left(D X R_{t-1}\right)$, harga riil ekspor rumput laut Indonesia di pasar Internasional $\left(D P X R_{t}\right)$, masing-masing dengan nilai elastisitas (dilihat dari koefisien regresinya) yang tergolong besar, yaitu masing-masing sebesar 0,31387; 0,47488; 0,24113 . Dilihat dari nilai elastisitas ini maka faktor yang dominan mempengaruhi penawaran ekspor rumput laut dalam jangka pendek adalah produksi rumput laut Indonesia di pasar Internasional.

Sementara itu, elastisitas peubah pendapatan nasional negara Internasional $\left(G N P_{t}\right)$ dan peubah tingkat bunga bank (DINT $\left.T_{t}\right)$ memiliki nilai koefisien yang relatif rendah, masing-masing sebesar 0,19896 dan 0,0796. Hal ini berarti bahwa kebijakan otoritas moneter (Bank Indonesia) yang cenderung menurunkan tingkat suku bunga ternyata berpengaruh terhadap peningkatan penawaran ekspor rumpit laut Indonesia di pasar Internasional dalam jangka pendek meskipun dengan elastisitas yang relatif rendah. Dengan kata lain, kebijakan moneter dari instrumen suku bunga mampu memberikan rangsangan bagi tumbuhnya investasi usaha produksi dan eksport rumput laut sehingga penawaran ekspor rumput laut Indonesia meningkat di pasar Internasional.

\section{KESIMPULAN DAN IMPLIKASI KEBIJAKAN}

\section{Kesimpulan}

Penawaran ekspor rumput laut Indonesia di pasar internasional dipengaruhi oleh ekspor rumput laut tahun sebelumnya, produksi rumput laut, harga ekspor rumput laut, 
pendapatan nasional negara mitra dagang utama, dan nilai tukar nominal rupiah terhadap US Dollar. Peubah utama yang memberikan pengaruh dominan terhadap ekspor rumput laut Indonesia adalah peubah ekspor rumput laut tahun sebelumnya dan produksi rumput laut. Sedangkan peubah suku bunga dan tingkat suku bunga bank dan harga domestik rumput laut belum menunjukan pengaruh yang nyata terhadap penawaran ekspor rumput laut Indonesia. Dengan kata lain, kebijakan moneter terkait dengan pergerakan suku bunga belum memberikan dorongan secara nyata bagi peningkatan ekspor rumput laut Indonesia. Disamping itu dengan adanya kebijakan yang berorientasi pada ekspor, maka harga domestik rumput laut juga pada akhirnya tidak mendukung ekspor rumput laut Indonesia di pasar internasional.

\section{Implikasi Kebijakan}

Penawaran ekspor rumput laut Indonesia di pasar internasional memiliki respon yang tinggi terhadap penawaran ekspor rumput laut periode satu tahun sebelumnya, produksi rumput laut, harga ekspor rumput laut Indonesia, pendapatan nasional negara mitra dagang utama, dan nilai tukar nominal rupiah terhadap US Dollar sebagaimana ditunjukkan oleh nilai koefisien paramater yang tergolong besar. Temuan ini, memberikan signal yang kuat bagi pembuat kebijakan (policy maker) khususnya yang berkaitan dengan upaya mendorong ekspor rumput laut Indonesia di pasar internasional ke depan. Diharapkan dengan memberikan dukungan secara khusus terhadap kelima peubah tersebut, daya saing ekspor komoditas rumput laut Indonesia di pasar internasional dapat lebih ditingkatkan. Peubah tingkat suku bunga dan harga domestik rumput laut Indonesia belum menunjukkan pengaruh yang nyata terhadap penawaran ekspor rumput laut Indonesia.

Berkaitan dengan hal tersebut, pemerintah dalam hal ini Departemen Kelautan dan Perikanan perlu mengupayakan agar harga ekspor maupun harga domestik rumput laut Indonesia dapat lebih kompetitif sehingga memberikan dorongan yang lebih tinggi kepada para pelaku usaha baik nelayan maupun para eksportir untuk terus meningkatkan produksi dan ekspor rumput lautnya. Di samping itu, pengendalian mutu (quality control) terhadap komoditas maupun produk olahan rumput laut Indonesia, sehingga dapat daya serap pasar baik potensial maupun aktual akan dapat lebih ditingkatkan.

\section{DAFTAR PUSTAKA}

Banerjee A. 1997. Co-Integration, Error Correction and Econometric Analysis of Non Stationary Data: Advance Texts in Econometrics. New York. Oxford University Press.

Branson W.H. and J.M. Litvack, 1981. Macroeconomics $2^{\text {nd }}$ Edition. Harper and Row Publisher. New York.

Dahuri, R. 2004 . Indonesia Berpotensi menjadi Produsen Ikan Terbesar. Mina Bahari, Vol. 2 (10).

Dahuri, R. 2004 ${ }^{\mathrm{b}}$. Rumput Laut: Banyak yang Mulai Melirik. Bisnis Indonesia, Selasa, 30 Maret 2004.

Dickey D.A. and W.A. Fuller 1974. Distribution of The Estimators for Autoregressive Time Series with a Unit Root. Journal of The American Statistical Association, Vol. 74.

Direktorat Jenderal Perikanan Budidaya. 2004. Statistik Perikanan Indonesia. Ditjen Perikanan. Departemen Kelautan dan Perikanan. Jakarta.

Engle, R.F. and C.W.J. Granger, 1987. Cointegration and Error Correction: Representation Estimation and Testing. Econometrica, Vol. 55: 76-251.

Fuller W.A. 1976. Introduction to Statistical Time Series. New York. John Wiley.

Granger C.W.J. and P. Newblod 1974.

Spurious Regresion in Econometric. Journal of Econometrics, Vol 2, No.1.

Granger C.W.J and P. Newblod 1977. Forecasting Economic Time Series. 
New York. Academic Press.

Gujarati D.N. 1995. Basic Econometric.

Third Edition. Singapore. McGraw-Hill International Edition. P.: 718-721.

Kindleberger C.P. and D.H. Lindert. 1982. International Economics. Richard D. Irwin. California.

Koutsoyiannis A. 1977. Theory of Econometrics, An Introductory Exposition of Econometric Methods. $2^{\text {nd }}$ Edition. Harper and Row Publisher Inc. New York.

Labys. W.C. 1973. Dinamic Comodity Model: Specification, Estimation and Simulation. Mass D.C. Helth and Company. Lexington.
Ma'ruf, F. 2005. Prospek dan Kendala Pengembangan Industri Karaginan di Indonesia. Paper dalam Temu Bisnis Pemanfaatan dan Pemasaran Karaginan. Pusat Riset pengolahan Produk dan Sosial Ekonomi Kelautan dan Perikanan. Jakarta.

Pindyck R.S. and D.L. Rubinfeld, 1991. Econometric Models End Economic Forecast. $3^{\text {rd }}$ Edition. McGraw-Hill International Editions. Singapore.

Philips P.C.B. 1986. Understanding Spurious regression in Econometrics. Journal of Econometrics, Vol. 33. 
LAMPIRAN : Data Peubah-peubah yang digunakan dalam Analisis Appendix: variables used in the analysis

\begin{tabular}{|c|c|c|c|c|c|c|c|}
\hline Tahun & XR & QR & PXR & PDR & GNP & NTR & INT \\
\hline 1975 & $2.052,40$ & $338.429 .887,00$ & 0,10 & 0,08 & 16,89 & 415,0 & 13,41 \\
\hline 1976 & $2.052,48$ & $3.384,33$ & 0,10 & 0,09 & 17,56 & 415,0 & 13,17 \\
\hline 1977 & $2.052,51$ & $3.392,43$ & 0,10 & 0,11 & 18,16 & 415,0 & 7,23 \\
\hline 1978 & $2.060,31$ & $3.214,30$ & 0,11 & 0,21 & 18,77 & 625,0 & 7,29 \\
\hline 1979 & 2471,00 & $3.524,41$ & 0,54 & 0,48 & 16,10 & 627,0 & 13,23 \\
\hline 1980 & $2.971,68$ & $3.211,42$ & 0,30 & 0,23 & 19,84 & 426,8 & 12,87 \\
\hline 1981 & $2.979,78$ & $3.385,41$ & 0,29 & 0,20 & 19,92 & 644,0 & 14,26 \\
\hline 1982 & $3.017,19$ & $3.485,42$ & 0,36 & 0,30 & 20,34 & 692,5 & 17,24 \\
\hline 1983 & $3.025,83$ & $3.925,41$ & 0,40 & 0,38 & 21,88 & 994,0 & 17,17 \\
\hline 1984 & $3.061,00$ & $4.885,37$ & 0,55 & 0,52 & 20,97 & $1.074,0$ & 17,33 \\
\hline 1985 & $4.446,00$ & $4.484,35$ & 0,53 & 0,49 & 32,37 & $1.925,0$ & 13,33 \\
\hline 1986 & $6.311,00$ & $6.579,60$ & 0,65 & 0,57 & 25,72 & $1.941,0$ & 13,00 \\
\hline 1987 & $9.182,00$ & $9.428,46$ & 0,37 & 0,24 & 26,17 & $1.950,0$ & 14,52 \\
\hline 1988 & $9.835,00$ & $10.112,79$ & 0,35 & 0,32 & 26,80 & $1.981,0$ & 15,00 \\
\hline 1989 & $12.020,00$ & $12.160,29$ & 0,50 & 0,48 & 39,61 & $2.720,0$ & 12,57 \\
\hline 1990 & $11.788,00$ & $10.836,05$ & 0,67 & 0,65 & 38,15 & $2.919,0$ & 13,97 \\
\hline 1991 & $11.305,00$ & $11.807,70$ & 0,50 & 0,47 & 23,07 & $2.992,0$ & 14,91 \\
\hline 1992 & $14.047,00$ & $14.886,52$ & 0,45 & 0,41 & 39,20 & $2.862,0$ & 11,99 \\
\hline 1993 & $16.562,00$ & $16.619,71$ & 0,51 & 0,49 & 32,52 & $2.810,0$ & 8,66 \\
\hline 1994 & $18.689,00$ & $18.750,90$ & 0,48 & 0,45 & 33,21 & $4.100,0$ & 14,25 \\
\hline 1995 & $22.958,00$ & $23.014,70$ & 0,65 & 0,53 & 49,47 & $4.210,0$ & 14,51 \\
\hline 1996 & $23.310,00$ & $23.768,25$ & 0,65 & 0,63 & 45,35 & $4.383,0$ & 15,08 \\
\hline 1997 & $23.810,84$ & $23.969,74$ & 0,75 & 0,72 & 46,34 & $4.650,0$ & 15,37 \\
\hline 1998 & $26.398,82$ & $26.826,52$ & 0,79 & 0,62 & 44,96 & $8.025,0$ & 15,39 \\
\hline 1999 & $27.752,99$ & $27.884,14$ & 0,85 & 0,81 & 46,34 & $7.085,0$ & 20,97 \\
\hline 2000 & $29.074,16$ & $29.461,82$ & 0,85 & 0,85 & 47,72 & $9.385,0$ & 16,35 \\
\hline 2001 & $30.363,13$ & $30.410,23$ & 0,86 & 0,82 & 47,10 & $9.462,0$ & 17,11 \\
\hline 2002 & $31.620,71$ & $31.793,09$ & 0,88 & 0,87 & 47,48 & $9.555,0$ & 17,50 \\
\hline 2003 & $32.847,64$ & $32.911,25$ & 0,91 & 0,88 & 48,86 & $9.649,0$ & 15,54 \\
\hline 2004 & $36.044,67$ & $36.269,61$ & 0,93 & 0,92 & 44,24 & $9.743,0$ & 14,10 \\
\hline 2005 & $36.212,54$ & $36.306,23$ & 0,97 & 0,96 & 46,62 & $9.837,0$ & 14,94 \\
\hline
\end{tabular}

